\title{
Effect of Paraffin Wax on the Properties of Mineral Oils
}

\author{
By A. P. Bjerregaard ${ }^{2}$
}

RESEARCH I ABORATORY, EMPIRE REFINERIES, INC., OKMULGEE, OKLAHOMA

$\mathbf{P}$ ARAFFIN wax decreases the viscosity of the more viscous mineral lubricating oils, raises the freezing point, and lowers the specific gravity. The amount of wax present may be quickly determined, with all necessary accuracy, by observing the freezing point and referring to Graph II $a$ of the present paper, where the percentage of paraffin wax is plotted against temperature.

Since paraffin wax occurs naturally as a component of many native crude petroleum oils, and therefore also in many intermediate and finished petroleum products, it is of importance to know what influence it exerts on the properties of the various other components of the petroleum, especially those with which it is naturally associated. These are the various viscous and so-called "nonviscous" lubricating oils.

The present study was made from the synthetic viewpoint. Known quantities of components of known properties were mixed, and the viscosity, freezing point, and specific gravity of the mixtures were determined.

\section{Materials Used}

PARAFFIN WAX - Three samples of paraffin wax were used: (1) prepared from Pennsylvania crude oil (nonasphaltic); (2) prepared from mid-continent crude oils, namely, a mixture of Illinois and Healdton crudes (semi-asphaltic); and (3) prepared from a central Oklahoma crude oil (semi-asphaltic).

The first two samples were prepared in the laboratory from "slack wax," which is the raw wax left in the filter presses of the refinery when the wax-containing fractions of the petroleum are filtered at a low temperature, usually about $15^{\circ}$ to $20^{\circ} \mathrm{F}$. This wax was pressed between blotting papers under a great weight, at a temperature of $80^{\circ}$ to $85^{\circ} \mathrm{F}$. until no more oil could be extracted. The blotting paper was changed from time to time as necessary. The resulting wax was melted at the lowest possible temperature, and an equal volume of petroleum spirit (usually called turpentine substitute) was added. After slow cooling, the excess of petroleum spirits was poured off, and the paraffin wax pressed as before. Next, the wax was exposed to the air for a short time, until all the remaining spirits had evaporated. The resulting wax was in each case free from oil, and it was not otherwise refined. By the "American method" the melting point of the Pennsylvania wax was $131^{\circ} \mathrm{F}$; t that of the midcontinent wax was $130.5^{\circ} \mathrm{F}$.

The third sample was a refined commercial wax of $122^{\circ} \mathrm{F}$. melting point ("American method"). It was prepared in the refinery in the usual manner, by "sweating" the slack wax and "filtering" or percolating through fuller's earth to remove any color that might be present. The sample contained 1.45 per cent oil.

oILs-The characteristics of the oil samples are tabulated in Table 1.

\section{Effect of Paraffin Wax on Viscosity}

The viscosities of varying mixtures of waxes and oils were determined with the Saybolt Universal viscosimeter in seconds at $100^{\circ} \mathrm{F}$. All mixtures are stated by weight. The data in Table 2 are plotted in Graph I.

Paraffin wax has no effect on viscosity when this value is low. On the other hand, with oils of higher viscosity, such as the commercial "neutral" lubricating oils, the addition of dissolved paraffin wax decidedly lowers the viscosity. The higher the viscosity the greater the effect of the paraffin wax.

The effect of the paraffin wax is approximately the same as it would have been if an oil of about 70-sec. viscosity had

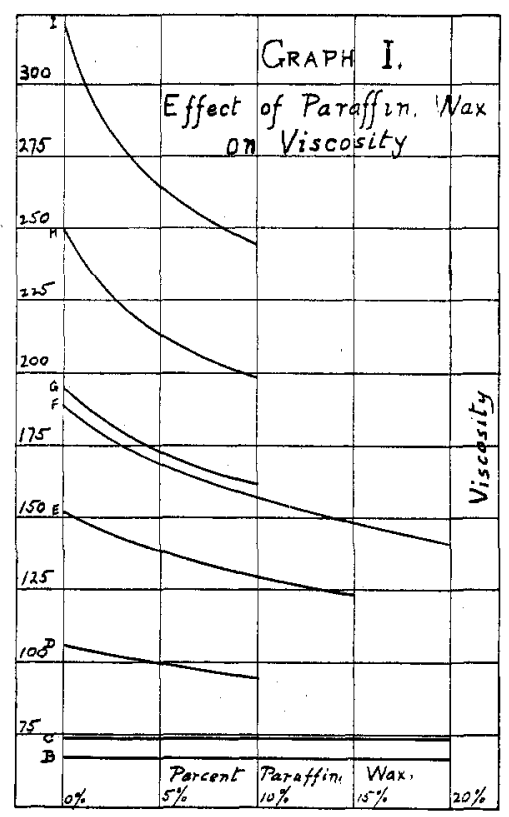
been added instead of the paraffin wax. In other words, the wax acts as a thin oil.

Molten paraffin wax is in fact a thin oil. A sample, like No. 3 of melting point $123^{\circ}$ F., "American method," showed a viscosity of 52 sec. at $125^{\circ} \mathrm{F}$., and of $46 \mathrm{sec}$. at $150^{\circ}$ F. Calculation from the observed figures to $100^{\circ} \mathrm{F}$. leads to approximately 70 sec. for the viscosity of the paraffin wax at $100^{\circ} \mathrm{F}$, on the assumption that it were liquid at that temperature.

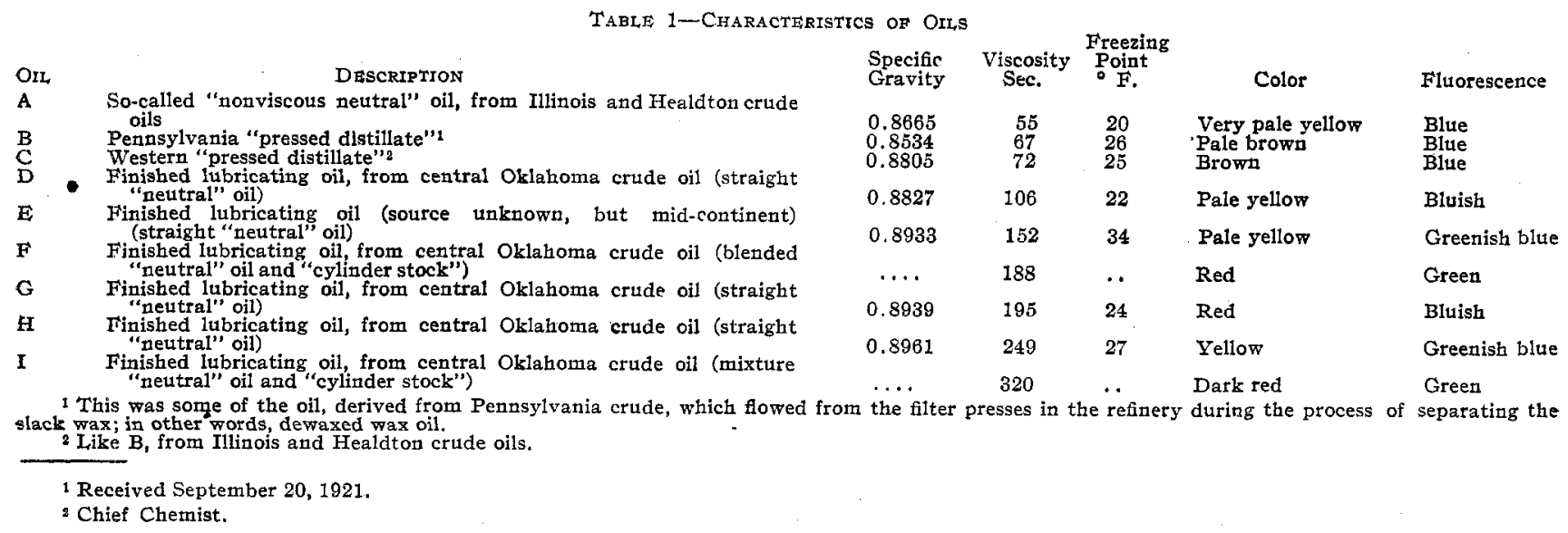


TABLE 2-EFFECT OF PARAFFin WAX ON Viscosity

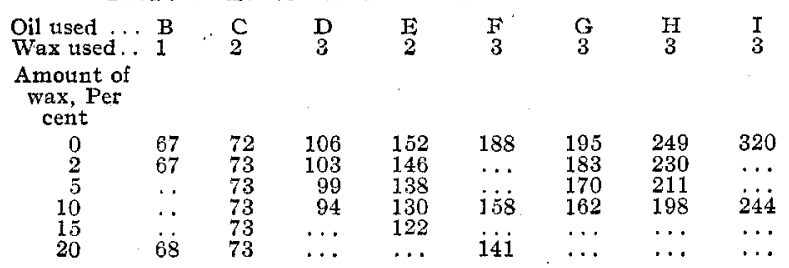

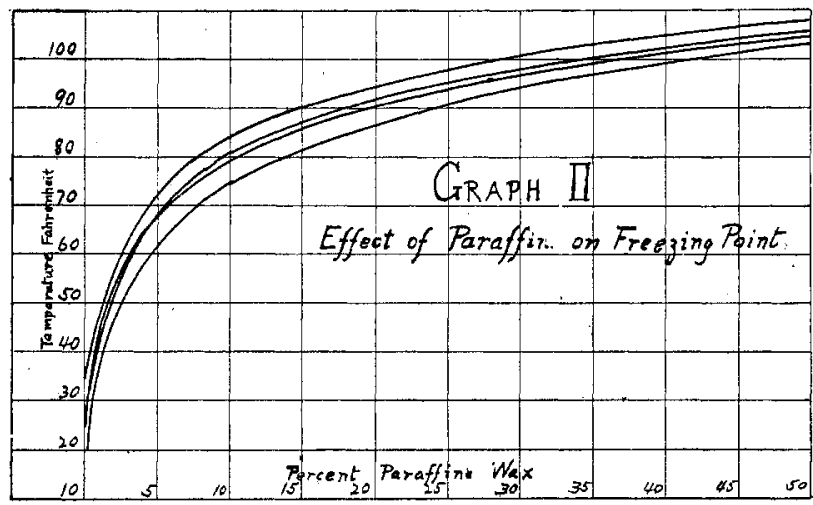

Effect of Paraffin Wax on Freezing Point

The freezing points of mixtures of oils and paraffin waxes were determined. The American Society for Testing Materials "Pour Test," D 47-18, was followed except that the actual temperature of solidification was observed and recorded instead of the next higher even $5^{\circ}$ or $10^{\circ}$ mark.

It may be remarked in passing that this freezing point is not the point of solidification of the whole mass of the oil and paraffin wax mixture, but is due only to the growth of a spongy network of paraffin wax crystals which retains the rest of the oil in its interstices. This is proved by the fact that if the solidified mass, without warming, is stirred, it becomes a liquid with admixed paraffin crystals suspended therein. When this is further cooled it again solidifies, but at a much lower temperature. In this manner, by successive coolings and stirrings, several different freezing points may be obtained with the same solution of paraffin wax in oil. Only the highest solidifying temperature found, without any disturbance of the oil, is considered in this series of experiments.

Table 3 shows the data obtained, some of which are plotted in Graph II.

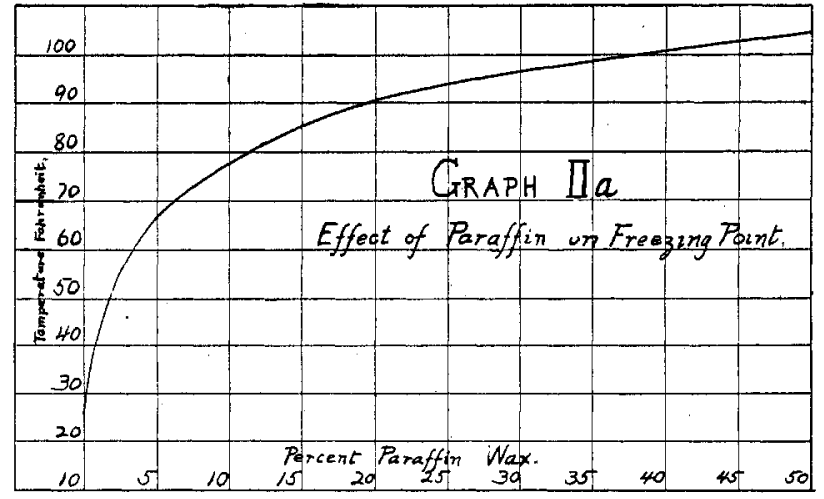

It will be noted that the freezing points of these mixtures do not depend at all upon the kind of oil used. While the freezing point does to some extent depend upon the freezing point of the oil used, the principal factor is the amount of paraffin wax present. Even a very small per cent of the wax causes a large rise in the freezing point. As more wax
Tabie 3-Effect of Paraffin Wax on Fremeing Point

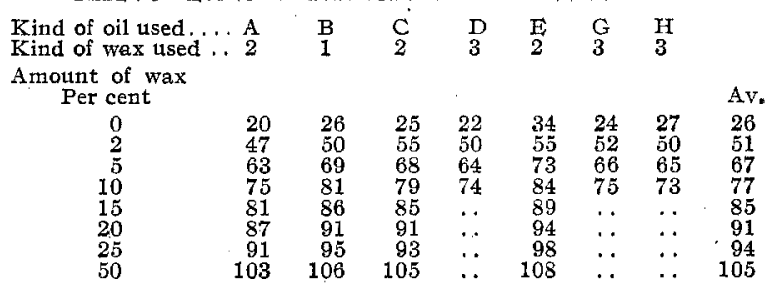

is added the increment of rise in the freezing point becomes less and less, as indicated in the graph.

The freezing points (before adding the paraffin wax) of the oils used are dependent on the amount of paraffin wax left in them by the manufacturing operations. It is possible to reduce them all to the same basis by simply shifting the location of the starting points on the graph all to the same place. The other end of the curve must not be shifted, because the wax is assumed to be the same in each case. Hence the curve will be shifted in a rotational way with the 100 per cent wax point as the center.

If by this means all the data be reduced to a common starting point, say at $26^{\circ} \mathrm{F}$, the freezing points of all the oil and paraffin mixtures will fall on the same curve, within the limits of experimental error. This is virtually the same as making the assumption that all the oils used had originally a freezing point of $26^{\circ} \mathrm{F}$., before adding the paraffin wax. The curve thus obtained is practically identical with that derived from the arithmetic averages of the freezing points for the mixtures with the same wax content. Such a curve is plotted in Graph II $a$ and the figures are shown in the last column in Table 3.

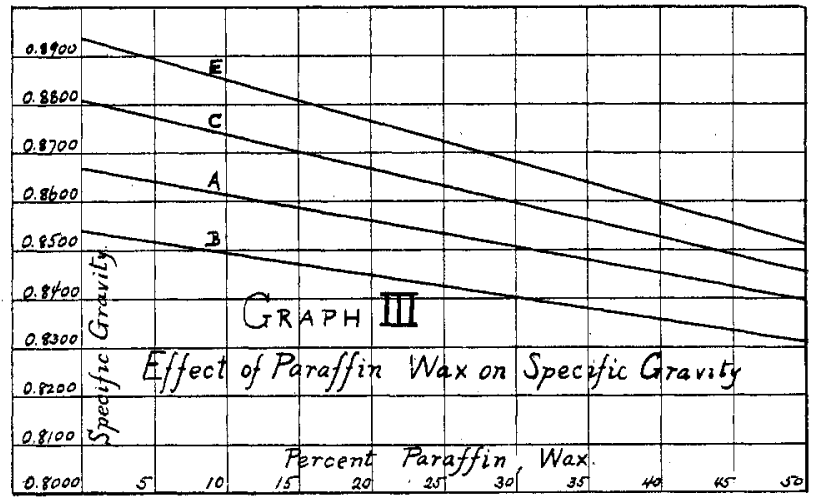

Graph II $a$ has been found very useful in the examination of wax distillates for paraffin wax content. Instead of the timeconsuming and inaccurate Holde method of estimating the wax content, all that is necessary is to determine the freezing point and refer to the curve of Graph IIa. Thus, if the freezing point is $70^{\circ} \mathrm{F}$., there is a wax content of 6.5 per cent together with 93.5 per cent of oil of $26^{\circ} \mathrm{F}$. freezing point. The writer has used this method for the past five years and has found it sufficiently accurate and reliable for all practical purposes.

\section{Effect of Paraffin Wax on Specimic Gravity}

The specific gravities of mixtures of paraffin wax and oils were determined by means of a hydrometer, while the mixture was warm enough for all the wax to be in clear solution. In Table 4 these determinations have all been reduced to their equivalents at $60^{\circ} \mathrm{F}$, by means of the tables commonly employed for that purpose in the petroleum industry.

Graph III (plotting the data of Table 4) shows clearly that the specific gravity becomes smaller with the addition of paraffin wax to the mineral oil, the more rapidly the heavier 